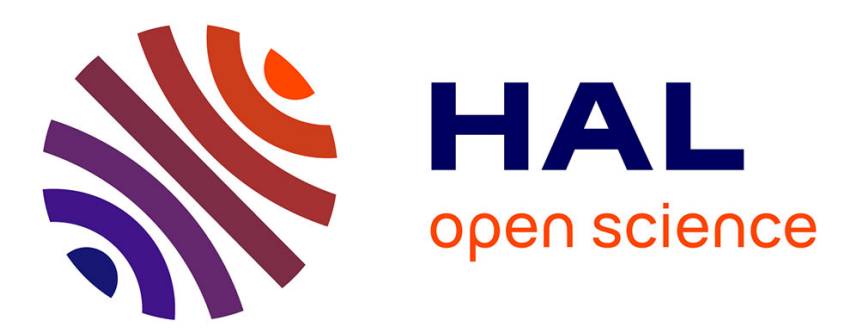

\title{
Modeling disruptions causing domino effects in urban guided transport systems faced by flood hazards
}

Michaël Gonzva, Bruno Barroca, Pierre-Etienne Gautier, Youssef Diab

\section{To cite this version:}

Michaël Gonzva, Bruno Barroca, Pierre-Etienne Gautier, Youssef Diab. Modeling disruptions causing domino effects in urban guided transport systems faced by flood hazards. Natural Hazards, 2017, 86 (1), pp.183-201. 10.1007/s11069-016-2680-7 . hal-01411363

\section{HAL Id: hal-01411363 https://hal.science/hal-01411363}

Submitted on 8 Jan 2018

HAL is a multi-disciplinary open access archive for the deposit and dissemination of scientific research documents, whether they are published or not. The documents may come from teaching and research institutions in France or abroad, or from public or private research centers.
L'archive ouverte pluridisciplinaire $\mathbf{H A L}$, est destinée au dépôt et à la diffusion de documents scientifiques de niveau recherche, publiés ou non, émanant des établissements d'enseignement et de recherche français ou étrangers, des laboratoires publics ou privés. 


\section{Modeling disruptions causing domino effects in urban guided transport systems faced by flood hazards}

\section{Michaël Gonzva, Bruno Barroca, Pierre- Étienne Gautier \& Youssef Diab}

\section{Natural Hazards}

Journal of the International Society for the Prevention and Mitigation of Natural Hazards

ISSN 0921-030X

Volume 86

Number 1

Nat Hazards (2017) 86:183-201

DOI 10.1007/s11069-016-2680-7

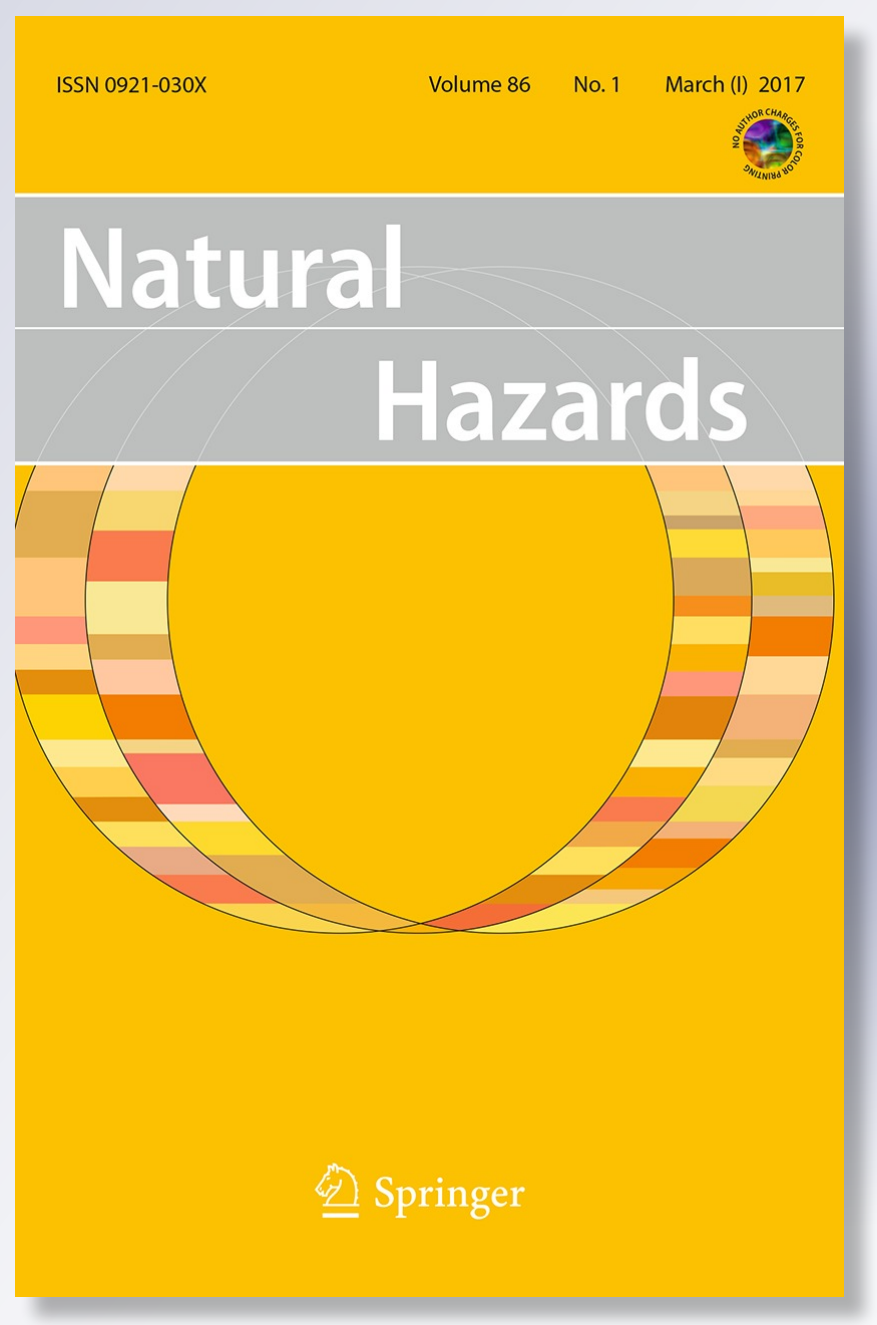

Springer 
Your article is protected by copyright and all rights are held exclusively by Springer Science +Business Media Dordrecht. This e-offprint is for personal use only and shall not be selfarchived in electronic repositories. If you wish to self-archive your article, please use the accepted manuscript version for posting on your own website. You may further deposit the accepted manuscript version in any repository, provided it is only made publicly available 12 months after official publication or later and provided acknowledgement is given to the original source of publication and a link is inserted to the published article on Springer's website. The link must be accompanied by the following text: "The final publication is available at link.springer.com". 


\title{
Modeling disruptions causing domino effects in urban guided transport systems faced by flood hazards
}

\author{
Michaël Gonzva $^{1}$ - Bruno Barroca ${ }^{2}$ Pierre-Étienne Gautier ${ }^{3}$. \\ Youssef Diab $^{4}$
}

Received: 6 October 2015/Accepted: 7 November 2016/Published online: 19 November 2016

(C) Springer Science+Business Media Dordrecht 2016

\begin{abstract}
Flood risks are the most frequent natural risks in the world. Their consequences are particularly serious when they affect technical systems in urban areas. Experience feedbacks on guided transport systems show that they are urban technical systems that are particularly vulnerable to this type of natural risk. The resilience concept is used in a systemic approach for making an accurate analysis of this type of natural risk. The purpose of this article is to provide an analysis of guided transport systems' resilience in the face of flood risks via a study of the failure mechanisms to which component elements of these systems are subjected. By using methods resulting from operational safety concepts and designing a computer tool, all the failure scenarios for components can be produced, together with their domino effects. In this way, our work provides a methodology for characterizing guided transport systems' vulnerability in the face of natural risks and for comparing this vulnerability depending on whether the system is in an underground, ground-level or overground configuration.
\end{abstract}

\footnotetext{
Michaël Gonzva

mgonzva@systra.com

Bruno Barroca

bruno.barroca@u-pem.fr

Pierre-Étienne Gautier

pegautier@systra.com

Youssef Diab

youssef.diab@u-pem.fr
}

1 SYSTRA and Paris-Est Marne-la-Vallée University (Lab’Urba Laboratory), 72 rue Henry Farman, 75015 Paris, France

2 DPLG Architect, Paris-Est Marne-la-Vallée University (Lab’Urba Laboratory), 6-8 av. Blaise Pascal - Champs-sur-Marne, 77455 Marne-la-Vallée Cedex 2, France

3 Scientific Director of the School of Engineering of the City of Paris (EIVP), Paris-Est Marne-laVallée University (Lab’Urba Laboratory), 6-8 av. Blaise Pascal - Champs-sur-Marne, 77455 Marne-la-Vallée Cedex 2, France

4 SYSTRA Vice-President of Innovation, 72, rue Henry Farman, 75015 Paris, France 
Keywords Rail transport $\cdot$ Floods $\cdot$ Simulation $\cdot$ Risk management

\section{Introduction}

Water-courses bursting their banks, marine submersion, rainwater run-off, rises in groundwater levels, etc. All these hazards are precursors of the most frequent natural risk in the world ${ }^{1}$ : the flood risk. The consequences of flood risks are all the more important as they generally occur on sites (plains, valleys, sea shores, etc.) suitable for human settlement. Therefore, in financial terms, the damage caused is very considerable, especially for technical systems, which are an integral part of towns and cities. Certain technical systems are identified as being "critical" infrastructures in scientific literature (Bouchon 2006; O'Rourke 2007) in view of populations' increasing dependence on them (La Porte 2006). Moreover, this dependence is likely to grow inasmuch as, since 2007, over half the world's population lives in towns and cities (UN-Habitat 2012), and this demographic trend is likely to increase over the coming years. These critical infrastructures, which constitute the backbone of modern societies (Ventura et al. 2010) and whose main characteristics have already been established (Kröger 2008), are clearly and collectively identified by a large number of international institutions (DHS 2006; PSC 2009; CEU 2008). The individual vulnerability of critical infrastructures becomes a major issue in urban risk management from the moment that it is likely to generate collective vulnerability on account of the relationships between the different infrastructures. It is clear that the relatively recent awareness of the numerous interactions fostered between each other by networks, infrastructures and urban services recognized as being critical, essential or vital (Robert and Morabito 2011) has totally modified risk management methods for urban environments. These interdependences may be sources of failures due to domino effects, as the failure of one infrastructure may directly or indirectly affect other infrastructures and thereby have an impact on large geographical areas (Rinaldi et al. 2001). The scientific community become increasingly interested in lifelines interdependencies, in recent years, and several methods are suggested to evaluate the resilience of an area affected by a disaster considering these infrastructures interdependencies (Cimellaro et al. 2014). Therefore, it would appear that scientific research on urban risk management is turning towards studying and modelling "complex systems" (Le Moigne 1999) and "systems of interdependent systems" (Kröger 2008). This evolution is revealed by the conceptual changeover in catastrophe risk management, going from the idea of protecting critical infrastructures towards a more systemic and global view of risk management (Bach et al. 2013). It is clear that, initially, management of natural risks affecting critical infrastructures has been centred on the notion of vulnerability, i.e. "the propensity of exposed elements such as physical or capital assets, as well as human beings and their livelihoods, to experience harm and suffer damage and loss when impacted by single or compound hazard events" (Birkmann et al. 2013). At present, however, research is turning towards a more systemic approach, which is taking form by calling on the resilience concept, mobilized in a large number of very different domains (Francis and Bekera 2014) and which can be defined in this communication by: "as a function indicating the capability to sustain a level of functionality or performance for a given lifeline networks over a period defined as the control time that is usually decided by owners or society (usually is the life cycle or the life span of the system)." (Cimellaro et al. 2010). In this approach, resilience is an important

1 EM-DAT: the International Disaster Database. 
concept for the disaster managements of complex systems such as urban transport systems and needs to be improved. Four dimensions along which resilience can be improved are be identifiable (Cimellaro et al. 2009). Robustness is the ability of elements or systems to withstand a given level of stress or demand without suffering degradation or loss of function; redundancy represents the capability to use alternative resources when the principal ones are either insufficient or missing; resourcefulness is the capacity to identify problems, establish priorities, and mobilize resources when conditions exist that threaten to disrupt a system; and rapidity is the capacity to meet priorities and achieve goals in a timely manner in order to avoid future disruption. The failure mechanisms due to domino effects within a given system facing a natural hazard totally impacted the robustness, resourcefulness and rapidity capacities. Therefore, existing holistic frameworks for measuring disaster resilience are able to provide the basis for development of quantitative models that assess the functionality and resilience of communities, infrastructures or services against extreme events and that take account the interdependencies among lifelines (Cimellaro and Arcidiacono 2013).

Transport infrastructures for both goods and persons are to be found amongst all the urban technical systems identified as being critical, it even being considered that the economy and national safety of countries such as the USA depend on them (PCCIP 2001). References treating the vulnerability of passenger-guided transport systems in the face of natural risks, especially flood risks, are numerous and are the subject of international research projects (Duinmeijer and Bouwknegt 2004; Cochran 2009; WEATHER project 2012; Oslakovic Stipanovic et al. 2013).

However, it is interesting to note that there is abundant knowledge of how the urban transport sector may contribute to climate change through greenhouse gas emissions. However, much less attention has been given to the potential impacts of climate change on urban transport systems, particularly concerning the effects of flooding on their performance (Suarez et al. 2005). For this reason, all guided transport systems appear to be vulnerable on material and functional levels, irrespective of whether they are underground, ground-level or overground systems. By nature, these systems are interdependent, inasmuch as each component's operation is closely linked to that of other components.

These interdependence notions also exist with the elements comprising transport systems' environment. Failures can spread from one initiator component towards the other components via these different interconnections. An interesting French incident highlighted the existence of such interdependencies within the components of a system. A severe thunderstorm actually occurred in Sarry, on the high-speed line between Paris and Lyon in September 2000. The extreme rainfall event produced an intense surface run-off that led to mudslides along the cutting of this area on the high-speed line. Water, mixed with solid materials, totally flooded the area. Moreover, the undersizing of the hydraulic structures caused their overflowing onto the pathway, which finally led to the transportation of ballast far from the track structure (Amblard et al. 2015). Hence, the disruption of the hydraulic components (pipes and ditches) generated through a domino effect the failures of the ballast and the catenary poles, until the traffic interruption of the line.

Therefore, the existing interdependencies between critical infrastructures at the scale of a connected systems network have an equivalent at the scale of a unique system: the innerdependencies meaning dependencies between the components of a critical infrastructure. These inner-dependencies have exactly the same effect in case of the occurrence of a natural hazard by initiating and spreading domino-effect failures within the system. Only the scale changes. 
This article proposes a method of analysing guided transport systems' resilience when faced by flood risks, in their three traditional configurations of installation: underground, ground and overground. Their resilience is analysed via the failure mechanisms to which they are subjected under flood conditions. It is clear that these mechanisms lead to numerous, complex failure scenarios. Modelling these scenarios that emerge through innerdependencies enables us to identify the components in the system that are successively damaged as a result of a disruption and, finally, allows to highlight ways of improving the resilience of the system through its robustness, resourcefulness and rapidity capacities. The article actually deals not with the resilience of guided transport systems in the sense of how redundant or elastic the overall transport system is at the city level. The resilience is not discussed here in the meaning of how the multi-modal redundancy, by using complementary non-guided systems, may improve the resilience of the overall system. The risk management aspects including rules and procedures to trigger and staff to mobilize are not the purpose of the article. The article is mainly focused on, firstly, an assessment of the technical and functional vulnerability of a guided transport system through the demonstrated cascading effects in the occurrence of a flood hazard and secondly, a comparison of these vulnerabilities according to the configurations of installation. The resilience is applied in the meaning of a systemic approach that allows to assess the direct and indirect disruptions within a guided transport system facing a flood hazard.

After a first section in which, the choices of methodology and postulates made in our research are presented and justified, a second section deals with the way in which these methodologies can be applied to guided transport systems. In a third section, the authors present the computer tool developed for producing the scenarios of the domino-effect failures that have been modelled. Lastly, the authors present the results obtained by modelling component interdependence.

\section{Materials}

In France, a guided transport system is defined as being a public transport system whereby the vehicles follow a determined trajectory for all or part of their journey, with the exception of those which circulate exclusively on the national rail network. ${ }^{2}$ Therefore, subways, trams, intercity railway and high-speed lines offering a regular transport service and not circulating on the national network are included.

There are many different types of guided transport systems throughout the world. These differences are essentially due to operating speeds, transport capacities, passenger flows and the configuration of the installation of the system. As far as subway systems are concerned, they run on all or part of their lines through tunnel-type underground structures (e.g. the Paris and London underground networks). Ground-level systems run on dedicated surface-level platforms (e.g. the Dijon or Jerusalem tram networks). Overground systems run with all or part of their lines on overhead structures such as viaducts and bridges (e.g. the Dubai and Hanoi metros). In the case of metro lines, it is important to note that the number of underground systems seems to be considerably higher than the number of ground-level or overground systems. In 2009, amongst 146 urban metro lines identified in 15 European countries and representing $2335 \mathrm{~km}$ of railway lines, $4 \%$ are overground, $24 \%$ are on ground level and $72 \%$ are underground (ERRAC and UITP 2012).

${ }^{2}$ Definition of French Ministry of Ecology, Sustainable Development and Energy. 
The component elements of a guided transport system can be determined by a structural analysis carried out prior to the actual functional analysis. In the structural analysis, the system under study is divided into several sub-system levels (Fig. 1).

Similarly, sub-systems are then broken down into components. For example, amongst other components, the "infrastructure" sub-system contains "sleepers" and "switch and crossing units". This break-down can be continued by separating "sleepers" into "anchor bolts", "screw spikes", etc., and the "switch and crossing units" component into "bearing plates", "insulated rail joints", "check rails", etc. However, in our research only the first three breakdown levels have been taken into consideration: in the form of systems, subsystems and components (Fig. 2). Models and tools for describing the vulnerable behaviour of a system facing a natural hazard revealed the particular attention paid to the structural analysis because even non-structural components can be sensitive to multiple hazard parameters and involve a systemic vulnerability (Cimellaro and Reinhorn, 2010).

Certain components are common to all installation configurations (e.g. rails), others are specific to the configuration under study (e.g. tunnels in an underground configuration), and others are positioned identically irrespective of the installation configuration (e.g. maintenance sites are always on ground level in all system installation configurations) (Table 1).

Other sub-systems and components could be added to the structural analysis for each configuration of installation. For instance, for underground-guided transport systems, the ventilation subsystem consisting of fan plants, ventilation shafts, ventilation and exhaust ducts or surface ventilation grids (where applicable) could be added. These components have been identified in past flooding disasters as a great source of vulnerability for underground guided transport sub-systems (NYSERDA, 2011). Another example relating to overground-guided transport systems: the bridge and viaduct piers. These components are also considered as a source of vulnerability because of potential scouring that could result in the destabilization of the piers and undermining the integrity of the superstructures. But, these sub-systems and the associated components can be considered as the entry point of the water flows in the system in case of flooding hazards, in the same way as stations accesses for instance. Thus, adding these will not basically modify the results of the functional analysis, the failure mode and effect analysis, the computer modelling which produces the successive failure scenarios due to domino effects (Fig. 3). Moreover, it is always possible to add specific structural and non-structural components relating to an installation configuration without modifying the functional analysis. Lastly, one of the main objective of the structural analysis is to get three similar systems (underground, ground, overground) in order to compare their vulnerability in case of flooding events using the proposed methodology (Fig. 3). So, adding some specific components seems to

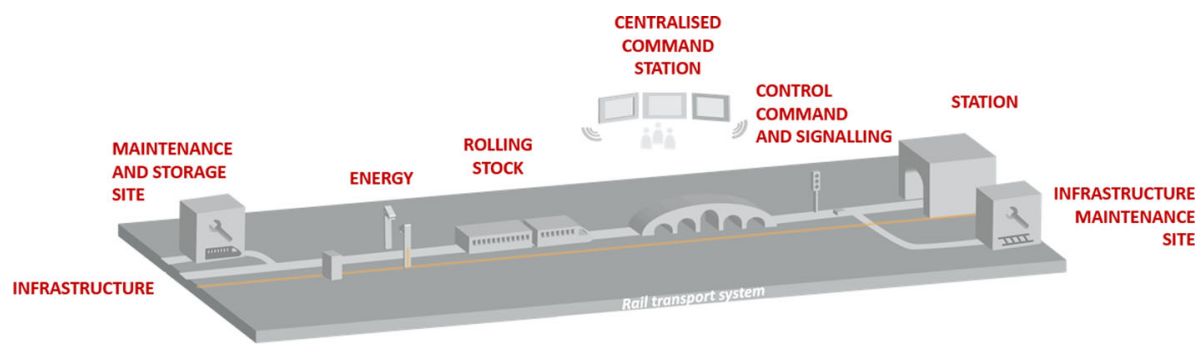

Fig. 1 Preliminary structural analysis of a generic guided transport system (Gonzva and Gautier 2014) 


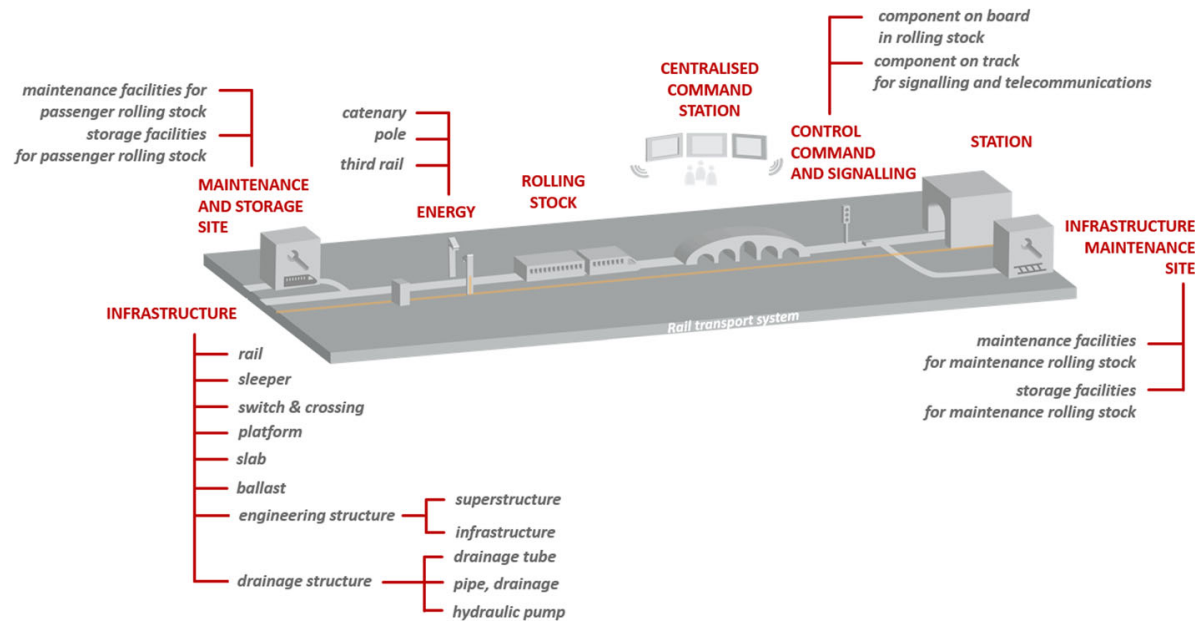

Fig. 2 Structural analysis of a generic guided transport system broken down into subsystems (in red block letters) and then into components (in grey italic letters)

be not relevant; for instance, dividing the "superstructure" component related to the overground configuration into "bridge deck" and "bridge piers" is not adequate for comparing the three configurations; the "superstructure" level is sufficient. However, for a single vulnerability assessment of a given installation configuration facing a flooding hazard, it would be necessary to add specific subsystems and components, but in a comparative approach, the structural analysis presented in Table 1. Structural analysis of a guided transport system as per the three normal installation configurations is appropriate.

\section{Methods}

Reflecting from a systemic point of view appears to be an opportunity for developing resilience strategies for critical infrastructures. Although modelling and predicting the behaviour of a critical infrastructure is challenging (Comesb and Van de Walle 2014), a systemic approach appears to be essential for:

- Understanding interdependencies by quantifying interconnections (Zimmerman and Restrepo 2006);

- Integrating all the interdependencies, irrespective of whether they are due to processes within the system, to external changes in the system's environment (Gallopín 2006) or to unexpected (Bach et al. 2013) or unforeseeable events;

- Determining failures due to domino effects between different urban technical networks considered to be critical (Lhomme et al. 2011).

The systemic, multi-dimensional approach towards which risk management practices are turning has led to developing methodological frameworks for assessing technical systems' resilience. Depending on their specific characteristics, the purpose of these conceptual frameworks is to incorporate a range of urban dimensions - social, cultural, environmental, territorial...-related to operating technical systems (Birkmann et al. 2013; Renschler et al. 2010), to highlight the dimensions that constitute resilience (Barroca and 
Table 1 Structural analysis of a guided transport system as per the three normal installation configurations

\begin{tabular}{|c|c|c|c|}
\hline \multirow[t]{2}{*}{ Component } & \multicolumn{3}{|l|}{ Level } \\
\hline & Underground & Ground & Overground \\
\hline \multicolumn{4}{|l|}{ Energy } \\
\hline Third rail & $\mathrm{U}^{\mathrm{a}}$ & $\mathrm{G}^{\mathrm{b}}$ & $\mathrm{O}^{\mathrm{c}}$ \\
\hline Catenary & $\mathrm{U}$ & $\mathrm{G}$ & $\mathrm{O}$ \\
\hline Catenary pole & $\mathrm{U}$ & G & $\mathrm{O}$ \\
\hline \multicolumn{4}{|l|}{ Control Command and Signalling } \\
\hline Component on board in rolling stock & $\mathrm{U}$ & $\mathrm{G}$ & $\mathrm{O}$ \\
\hline Component for signalling and telecommunications & $\mathrm{U}$ & G & $\mathrm{O}$ \\
\hline \multicolumn{4}{|l|}{ Maintenance and Storage Site (M.S.S.) } \\
\hline Maintenance facilities for passenger rolling stock & G & G & $\mathrm{G}$ \\
\hline Storage facilities for passenger rolling stock & G & G & G \\
\hline \multicolumn{4}{|l|}{ Infrastructure Maintenance Site (I.M.S.) } \\
\hline "Maintenance" facilities for maintenance rolling stock & G & G & $\mathrm{G}$ \\
\hline "Storage" facilities for maintenance rolling stock & G & G & $\mathrm{G}$ \\
\hline Centralized Command Station (C.C.S.) & $\mathrm{U}$ & G & $\mathrm{O}$ \\
\hline Station & $\mathrm{U}$ & G & $\mathrm{O}$ \\
\hline Rolling stock & $\mathrm{U}$ & G & $\mathrm{O}$ \\
\hline \multicolumn{4}{|l|}{ Infrastructure } \\
\hline Rail & $\mathrm{U}$ & G & $\mathrm{O}$ \\
\hline Sleeper & $\mathrm{U}$ & G & $\mathrm{O}$ \\
\hline Switch and crossing unit & $\mathrm{U}$ & G & $\mathrm{O}$ \\
\hline Platform & $\mathrm{U}$ & G & $\mathrm{O}$ \\
\hline Slab track (non-ballasted track configuration) & $\mathrm{U}$ & $\mathrm{G}$ & $\mathrm{O}$ \\
\hline Ballast (ballasted track configuration) & $\mathrm{U}$ & G & $\mathrm{O}$ \\
\hline \multicolumn{4}{|l|}{ Engineering structure } \\
\hline Superstructure: bridge, viaduct, elevated section... & - & - & $\mathrm{O}$ \\
\hline Infrastructure: tunnel & $\mathrm{U}$ & - & - \\
\hline \multicolumn{4}{|l|}{ Drainage structure } \\
\hline Drainage tube & - & - & $\mathrm{O}$ \\
\hline Pipe, drainage ditch & - & $\mathrm{G}$ & - \\
\hline Hydraulic pump & $\mathrm{U}$ & - & - \\
\hline
\end{tabular}

${ }^{a}$ Component set up at underground level (U)

b Component set up at ground level $(\mathrm{G})$

${ }^{c}$ Component set up at overground level (O)

Serre 2013; Bruneau et al. 2003), or to establish indicators of performance and intrinsic resilience capacities (Francis and Bekera 2014; Lhomme et al. 2010). Theoretical flexibility is an essential property for these conceptual frameworks and, more generally, for all methodologies devised for analysing technical system resilience. It is clear that flexibility is essential as risk and vulnerability are processes that are dynamic by nature, that is to say, they change over time, and nonlinearity and complexity seem to be key characteristics for 
models of disaster risk systems (Birkmann et al. 2013). Lastly, one of the major issues in these methodologies comprises taking account of the interconnections between technical systems, because, as soon as a hazard affects a system, it can spread to other systems, have an impact on their operation and even significantly increase their vulnerability in the face of random failures (Buldyrev et al. 2010). An analysis of technical systems' resilience would therefore appear to be essential for converging towards urban resilience.

Choosing to implement methods resulting from operational safety concepts for studying the resilience of guided transport systems faced by flood risks can be justified on several counts (Gonzva et al. 2014). Firstly, operational safety is suitable for our problem inasmuch as it consists of knowing, assessing, anticipating, measuring and mastering failures in technological systems in order to limit the consequences of any such failures on human health and safety, on productivity and on the environment (Noyes and Peres 2007). To succeed in this, modelling using operational safety methods is based on functional modelling (Serre 2005), which consist of determining the interactions between the components of a system and its environment, in order to formally establish the links between functional failures, their causes and their effects (Serre et al. 2007). The second reason is that methods resulting from operational safety concepts can be considered as being a wide range of methods that are all at the service of risk management (Lhomme 2012), and mainly for risks affecting urban systems. Lastly, and this is the third reason: recent applied research work uses these methods efficiently when modelling the way complex urban systems function when they are faced with flood risks (Serre 2005; Vuillet 2012; Lhomme 2012).

Functional analysis (FA) is one of these methods. It enables the way systems operate to be modelled on the basis of two mutually dependent analyses: structural analysis and functional analysis. Structural analysis enables the positions and relations between different components in the system to be defined in order to formulate the functions of each component in the functional analysis. Two tools are then used for representing the system: the functional block diagram (FBD) and the functional analysis table (FAT) (Zwingelstein 1996). The FBD is a graphic representation of the system, which shows the interactions between system components and the elements of its external environment. The FAT is the logical continuation of the FBD analysis as it brings all the system's identified functions together. In addition, another method often applied after the FA is the failure mode and effects analysis (FMEA). The FMEA is a particularly efficient method of analysing failure modes and is used for structuring information on degradation in the form of tables: performance losses, their causes and their effects (Talon et al. 2009). By considering each system component and by analysing failure modes, the method provides a better understanding of how the system functions, for example, before, during and after flooding (Lhomme 2012). Lastly, a third operational safety method enables the results obtained by the FMEA to be modelled: events trees. These trees give a graphic representation of the sequence of events formed by an initiator event and a combination of successive failures.

As a result, in an approach for analysing the resilience of urban technical systems, three methods resulting from the operational safety concept are used consecutively (Serre et al. 2007): functional analysis, failure mode and effects analysis and events trees. In this article, the purpose of these choices of methodology is to demonstrate the following postulates: by using a combination of operational safety methods, it is possible to:

- Characterize the vulnerability of guided transport systems in the face of natural risks;

- Compare the vulnerability of guided transport systems in the face of natural risks depending on their configuration of installation (underground, ground level and overground). 


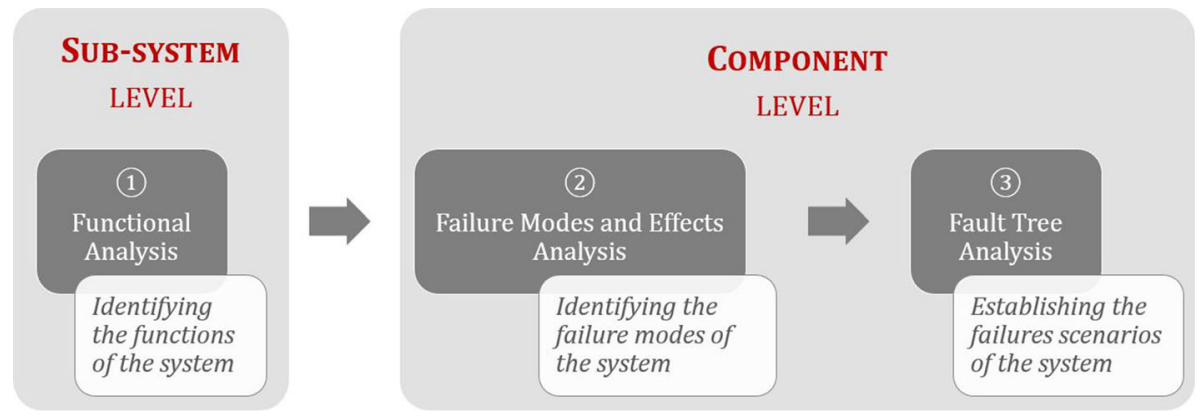

Fig. 3 Structural analysis and methods applied successively. The functional analysis is applied on subsystem levels, the FMEA and events trees are applied on component levels

Flood risks are presented as a demonstration for these postulates and as a subject for applying the methodologies selected (Fig. 3).

\section{Results}

\subsection{Functional analysis of a guided transport system}

On the basis of the structural analysis, the FA enables the types of relationship and the interactions to be determined between the different components in a system. Three types of interaction between components are taken into consideration:

- In normal situations:

- Contact relationships, materializing the existence of at least one physical contact between two elements;

- Dependence relationships, indicating that the creation of a flow from a first component to a second component is conditioned by the fact that the first component operates correctly.

- In crisis situations (during flooding):

- Vulnerability relationships, revealing a qualitative vulnerability level to flood risks for each component.

These interactions are represented in the form of an FBD. In this way, the three configurations of installation (underground, ground-level and overground) can be assessed on the basis of two possible situations: 6 FBD have been created for representing the system. The FBD of a ground system in a normal situation is presented in Fig. 4. All the functions carried out by each component are determined on the basis of these FBD.

\subsection{FMEA of a guided transport system subject to hydrologic risks}

The purpose of the FMEA made in this research process is to analyse the failure modes of all the components in the system for the three configurations of installation, when they are subjected to a hydrologic hazard disruption (heavy rain, flooding, etc.). Three FMEA have 


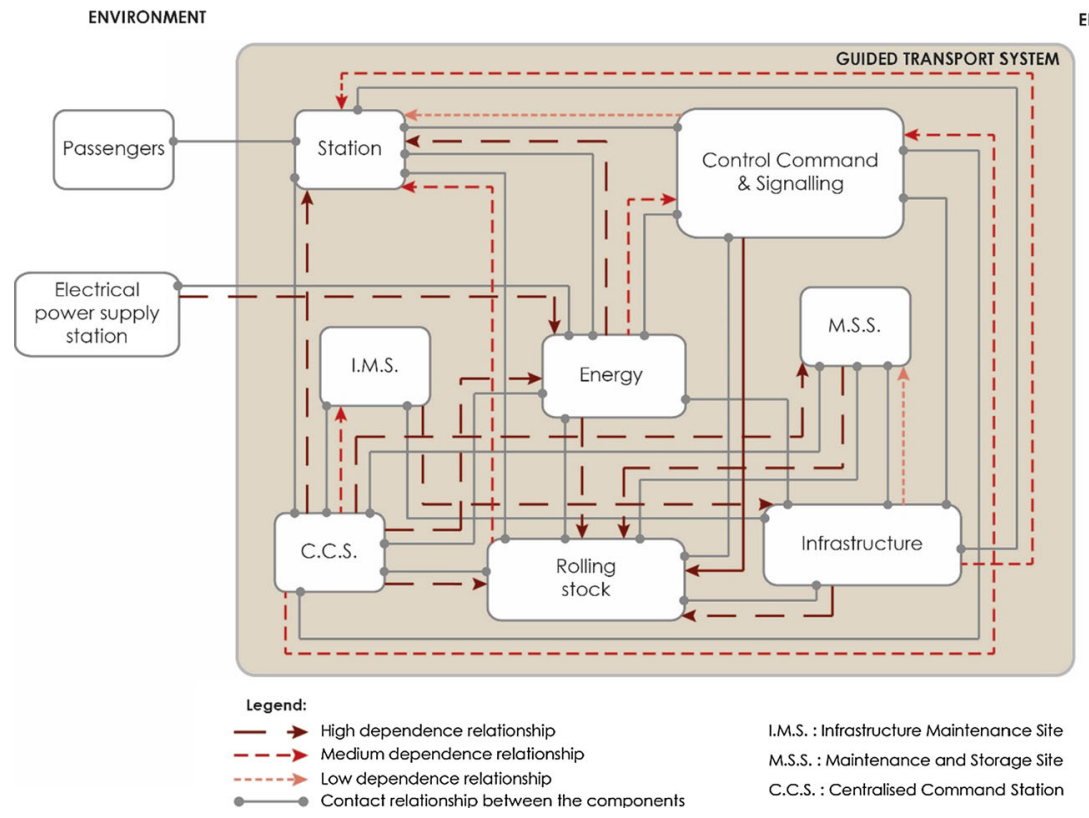

Fig. 4 Functional block diagram (FBD) of a ground-level guided transport system in a normal situation (Gonzva et al. 2014)

been made: a first one for overground systems, a second one for ground-level systems and a third one for underground systems.

The FMEA, represented in the form of a summary chart, lists: components, with identifiers, the sub-system of which they are a part, the functions provided by the component (numbered), the failure mode, which, in our study, corresponds to the nonachievement of these functions due to flooding, the events causing the failure mode to occur and, lastly, the effects of the component's dysfunction on the system (Table 2). Under these conditions, by means of the FMEA, it is possible to structure information on disruptions for each component (Lhomme et al. 2011).

Table 2 Extract of the FMEA produced in the case of guided transport systems in the face of a hydrology hazard

\begin{tabular}{|c|c|c|c|c|c|c|c|}
\hline $\begin{array}{l}\text { Sub- } \\
\text { system }\end{array}$ & $\begin{array}{l}\text { Component } \\
\text { identifier }\end{array}$ & Component & $\begin{array}{l}\text { Function } \\
\text { No. }\end{array}$ & Function & Failure mode & Cause & Effect \\
\hline$\ldots$ & $\ldots$ & $\ldots$ & $\ldots$ & $\ldots$ & $\ldots$ & $\ldots$ & $\ldots$ \\
\hline Energy & En_S_1 & Catenary & 4 & $\begin{array}{l}\text { Providing } \\
\text { traction } \\
\text { power } \\
\text { supply to } \\
\text { the } \\
\text { vehicles }\end{array}$ & $\begin{array}{l}\text { Not } \\
\text { providing } \\
\text { traction } \\
\text { power } \\
\text { supply to } \\
\text { the vehicles }\end{array}$ & $\begin{array}{l}\text { Breaking } \\
\text { of the } \\
\text { catenary }\end{array}$ & $\begin{array}{l}\text { Shutting } \\
\text { down } \\
\text { electrical } \\
\text { power } \\
\text { supply }\end{array}$ \\
\hline$\cdots$ & $\cdots$ & $\cdots$ & $\cdots$ & $\cdots$ & $\ldots$ & $\ldots$ & $\cdots$ \\
\hline
\end{tabular}


The two last columns "cause" and "effect" are exploited by the computer tool presented below.

\subsection{Events Tree for a guided transport system subject to hydrologic risks}

"Failure scenarios" can be drawn up on the basis of the FMEA. These scenarios correspond traditionally to events trees (Zwingelstein 1996), which provide a graphic display of all the successive failures of different components, which, in turn, lead to a system's global failure (Fig. 5). In this way, the scenarios reflect the functional interdependence that exists between all the components in a system. When a hydrology hazard occurs, it is this interdependence, inherent to the system's different elements, that leads to a chain of failures and, finally, to the overall dysfunction of the transport system (Gonzva et al. 2015).

Having said this, it must be recalled that the FMEA is a powerful method inasmuch as it enables us to make an exhaustive analysis for determining all the failures to which each component is likely to be subjected. For each of the three configurations of installation, about sixty functions and over three hundred cause-effect pairs have been determined (a function's failure may have several causes and therefore give rise to several effects). Two questions are raised at this point. How to use the exhaustiveness of the FMEA method for exploiting all the information it contains? How to be exhaustive when producing all the failure scenarios due to interdependences? Scientific and technical replies have been found to these two questions by creating a computer tool.

\subsection{A tool for analysing interdependence mechanisms in domino-effect failure scenarios}

A systemic approach to the failures to which a guided transport system is subjected when facing a hydrology hazard has been developed on the basis of a simulated original failure (initial cause). This is followed by determining all the failures induced by the initial failure. Component dysfunctions then spread from neighbour to neighbour (effect 1, generating effect 2, generating...) thereby creating failure scenarios. A database has been created to study this phenomenon. It contains all the scenarios obtained by the FMEA. For automating the creation of links between failures where the induced effect of the initial

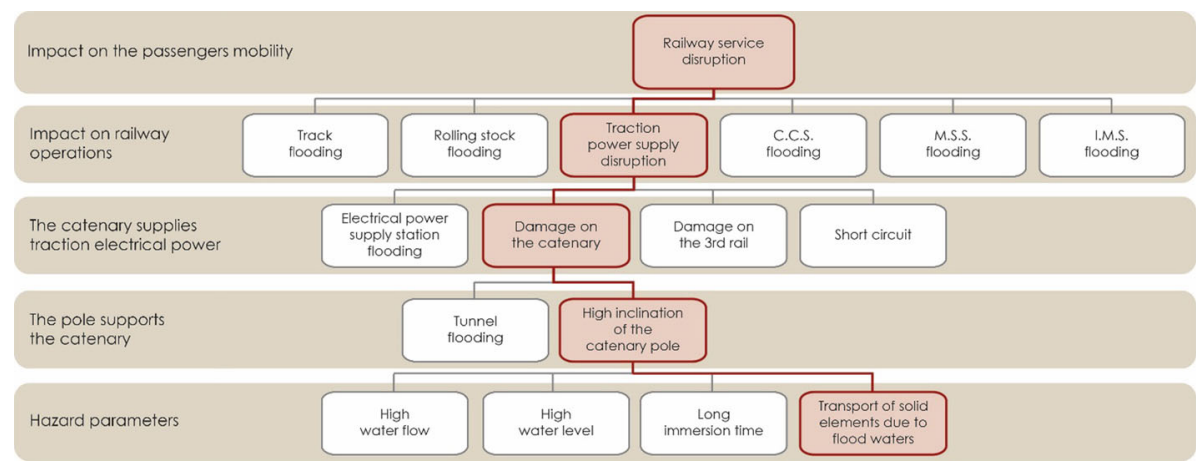

Fig. 5 Example of a failure scenario produced using an FMEA of underground systems (Gonzva et al. 2014) 
failure is nothing else but the cause of the second failure, a "cause and effect" typology needs to be developed. In this way, 62 cause and effect headings have been defined. Once the typology was established, an algorithm was developed for determining direct causeeffect relationships between all the components by successive iterations. The principle is as follows: one by one, the algorithm compares the headings contained in the "effect" column of a component with the headings in the "cause" column of another component. When a relationship is established between an "effect" heading and a "cause" heading which means that an effect heading and a cause heading are equal, an interdependence relationship exists. The algorithm stops whenever there is no new effect (iteration $n+1$ ) to be associated with a cause (iteration $n$ ) for each component. On every iteration, i.e. every time a direct cause-effect relationship is established between two components, the algorithm keeps the identifiers for every component with a failure from one component to the next. In this way, a "successive failures matrix" is obtained. In the matrix, the lines represent the domino-effect dysfunctions of the components in the system: the failure scenarios (Fig. 6).

A very large number of results are obtained by automating requests within the database. For example, the algorithm converged after producing almost 10,000 lines in the matrix for a ground-level configuration (Table 3). The successive iterations generate new lines on an exponential growth curve (Fig. 7). However, these thousands of lines have to be processed - these thousands of failure scenarios - to be able to exploit them. The objectives of processing data in this way are as follows:

1. To delete duplicated lines, i.e. scenarios containing exactly the same links between components;

2. To delete lines where a component appears more than once: they have no physical meaning as a component can only be considered as failing one single time;

3. To delete lines whose content is included in other lines: as the objective is to determine

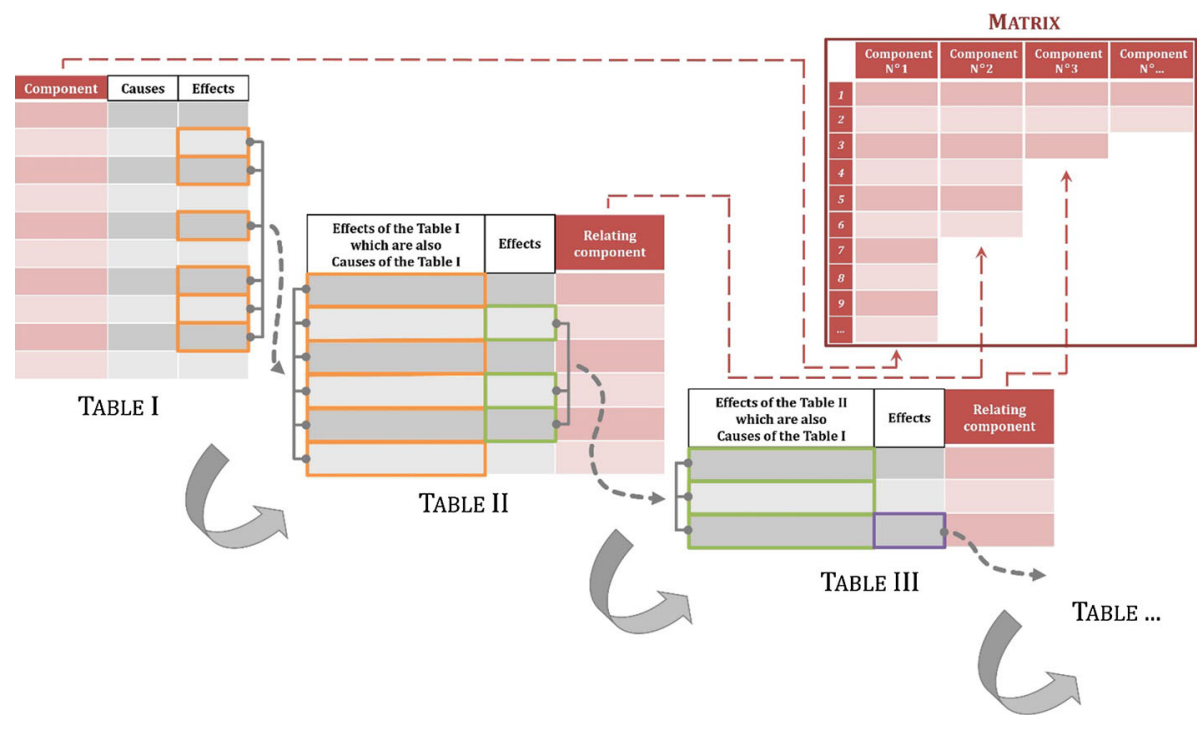

Fig. 6 Methodology for computer tool automation

all the domino-effect failures, sub-scenarios are already taken into account. 
Table 3 The number of successive failure scenarios before data processing

The bold numbers correspond to the last iteration after which the number of successive failure scenarios stop increasing

\begin{tabular}{lcll}
\hline & Underground & Ground & Overground \\
\hline Iteration 1 & 325 & 318 & 343 \\
Iteration 2 & 1179 & 1057 & 1218 \\
Iteration 3 & 3291 & 1985 & 2494 \\
Iteration 4 & 6359 & 3015 & 4320 \\
Iteration 5 & 11,188 & 4036 & 6531 \\
Iteration 6 & 16,102 & 4526 & 8737 \\
Iteration 7 & 20,363 & $\mathbf{4 6 4 6}$ & 9633 \\
Iteration 8 & 23,011 & 4646 & $\mathbf{9 7 2 9}$ \\
Iteration 9 & $\mathbf{2 3 , 5 2 3}$ & - & 9729 \\
Iteration 10 & 23,523 & - & - \\
\hline
\end{tabular}

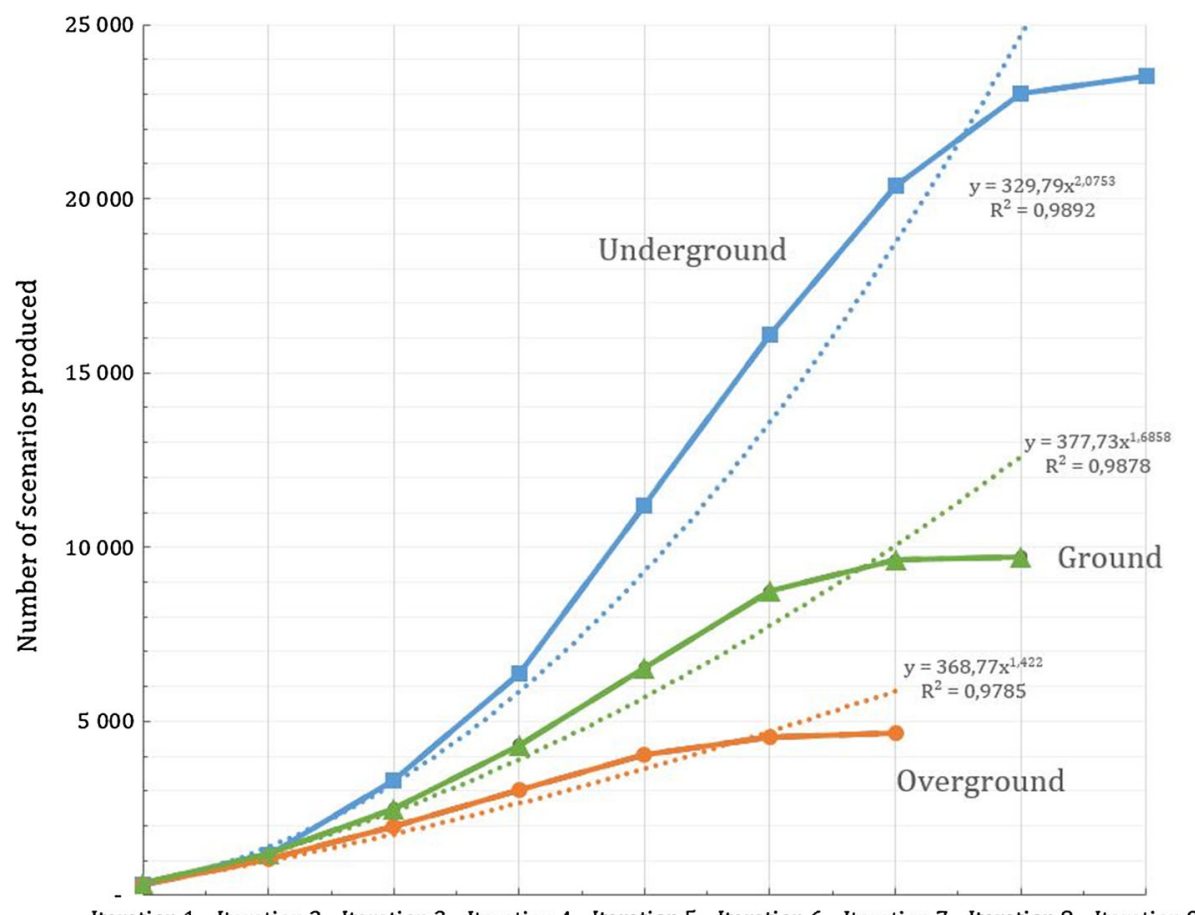

Fig. 7 Curves (solid lines) represent the numbers of experimental scenarios obtained with the computer tool and their associated curves (dotted lines) represent theoretical adjustment curves. The theoretical curves where adjustment is optimal grow exponentially (power function)

Data processed in this way provide us with three matrixes (Table 4), corresponding to the three construction configurations (underground, ground-level, overground), where lines contain single failure scenarios possessing a physical sense that can be interpreted. 
Table 4 Extract of the matrix for successive failure scenarios obtained with the computer tool in the case of a ground-level configuration

\begin{tabular}{llllllll}
\hline \multirow{2}{*}{ No. of failure scenarios } & \multicolumn{2}{l}{ Components } \\
\cline { 2 - 8 } & No. 1 & No. 2 & No. 3 & No. 4 & No. 5 & No. 6 & No. 7 \\
\hline$\ldots$ & $\ldots$ & $\ldots$ & $\ldots$ & $\ldots$ & $\ldots$ & $\ldots$ & $\ldots$ \\
85 & $\ldots$ & $\ldots$ & & & \\
86 & I_S_7 & CCS_S_2 & CCS_S_1 & G_S & & & \\
87 & I_S_7 & G_S & CCS_S_1 & CCS_S_2 & & & \\
88 & I_S_8 & CCS_S_2 & CCS_S_1 & G_S & & & \\
89 & I_S_7 & G_S & MR_S & SMR_1 & SMR_2 & & \\
90 & I_S_7 & G_S & I_S_5 & I_S_2 & I_S_4 & & \\
$\ldots$ & I_S_7 & G_S & I_S_5 & I_S_4 & I_S_2 & & \\
\hline
\end{tabular}

\subsection{Analysis of the results obtained}

The quality of the failure scenarios obtained is totally conditioned by the quality of the FMEA that has been made beforehand. In our research, the FMEA has been carried out together with experts on rail sub-systems, in order to make an accurate identification of the failure modes for each component, their causes of failure and the effects on other components. Moreover, the granulometry level chosen for breaking down the system to component level appears to be optimal for applying the methodology, inasmuch as it is not relevant to break the system down any further as identifying interactions between different elements would become fastidious and non-representative of real relationships. Lastly, a mean of improvement for specifying the precise origin of vulnerabilities would be to apply the methodology to components in each sub-system considered independently and not to all the components in the system. By means of this process, it could be possible to produce failure scenarios specific to a given sub-system, determine the origins of its vulnerability in face of a hydrology hazard and, in this way, highlight components that need to be made more reliable in a hierarchical way.

The results obtained are specific to a given natural hazard, the hydrologic hazard. The successive failure scenarios presented in this article are therefore limited to the vulnerability of guided transport systems in the face of hydrologic hazards. The whole methodology would need to be reapplied for taking account of other natural hazards.

In this way, mobilizing methodologies resulting from operational safety methods validates the scientific postulates proposed in this article: by using a combination of operational safety methods, it is possible to characterize the vulnerability of guided transport systems in the face of natural hazards, on the one hand, and compare the vulnerability of guided transport systems depending on their configuration of installation on the other hand. The case of hydrologic risks is used as a demonstration for applying the choices made in terms of methodology.

The computer tool developed for this study of the resilience of guided transport systems in the face of hydrologic risks highlights the successive failure scenarios for components in the system. This approach provides a systemic view of the effects of hydrologic hazards (rain-storms, flooding, etc.). Two main conclusions emerge from the study. Firstly, the underground configuration of installation proves to generate considerably more dominoeffect failure scenarios than the other two configurations (Table 5). Therefore, 
Table 5 Number of successive failure scenarios produced after data processing

\begin{tabular}{lll}
\hline Underground & Ground & Overground \\
\hline 663 & 105 & 206 \\
\hline
\end{tabular}

underground installations appear to intrinsically amplify the functional interdependences that exist between components, and, in this way, provoke potential failures in hydrologic hazard situations that are more important in terms of domino effect. Secondly, $80 \%$ of the scenarios obtained for the underground configuration contain between 4 and 6 components, whereas the same proportion of scenarios obtained for the two other configurations contain between 2 and 3 components. Therefore, creating an underground guided transport system intensifies the domino-effect failure process, which potentially spreads further, i.e. it involves a larger number of components in each scenario.

Even so, the underground installation configuration must not necessarily be excluded in a weather context that is favourable to hydrologic hazards. Results are semi-qualitative inasmuch as they highlight and prioritize components depending on the overall vulnerability of the system generated whenever they fail. Therefore, from the point of view of the operational perimeter covered by these results, they indicate components which need to be protected in priority for each configuration of installation for reducing the system's vulnerability. Results obtained for underground installations indicate that improving component reliability is a more complex task under these conditions. Therefore, this approach offers a relatively detailed way, as far as components are concerned, of enhancing guided transport systems' resilience in the face of hydrologic hazards.

\section{Conclusion}

The purpose of this article is to analyse the resilience of guided transport systems in the face of flood risks, depending on their three traditional configurations on installation: underground, ground-level and overground. This resilience analysis has been tackled by using the failure mechanisms to which systems in hydrologic hazard situations are subjected. By modelling these mechanisms, which leads to a large number of complex domino-effect failures, the most vulnerable components in systems can be identified. Modelling is done by using a number of methodologies to be found in operational safety concepts: functional analysis, failure mode and effects analysis and events trees.

A computer tool has been developed for this study to precisely characterize the vulnerability of the components' system from the particular failures due to domino effect. From these results, it can be possible either to reduce the vulnerability by increasing reliability of specific components and/or to improve the resilience through the implementation of actions accelerating the recovery relating to post-natural hazard event.

This tool also possesses several points of interest. Firstly, it fully exploits the exhaustiveness of the FMEA, the tool's central element, by automating the dysfunction identification process. Secondly, it provides a systemic approach to vulnerability in hydrologic hazard conditions by showing the system's overall response on the basis of intermediate responses provided by its different components. This systemic approach is a necessary step towards designing resilient systems.

The underground configuration of installation for a guided transport system generates more failure scenarios under hydrologic hazard conditions than ground or overground 
installations. Underground configurations appear to produce a larger number of dominoeffect dysfunction possibilities on components. This conclusion could be confirmed by experience feedbacks on the increased vulnerability of underground transport systems in the face of flooding (Compton et al. 2002) illustrated by events such as the Prague metro floods in 2001, where almost $20 \mathrm{~km}$ of lines and 19 underground stations were under water and out of service for several months (Chamra 2006).

The approach used for computer processing enables the exhaustive nature of the FMEA to be exploited in full. However, when considered from an identical point of view, the hundreds of failure scenarios obtained do not apparently possess the same likelihood of occurring. The purpose of our research is to draw up an exhaustive list all the events trees and to identify domino effects without trying to distinguish the events that are the most likely to occur.

A wide range of possibilities result from this work. Firstly, by working statistically on data on all the successive failure scenarios, it is possible to determine the role played by each component in failure scenarios. It is most certainly interesting to know whether a given component is usually at the origin of scenarios or, on the contrary, at their conclusion. In this way, components' aggressiveness or sensitiveness can be brought to light. Secondly, all the failure scenarios are considered to be possible. The preliminary approach defended in this article is based on an ambition to obtain an exhaustive range of scenarios. Allocating probabilities of occurrence to these scenarios, obtained by mathematical simulations, experience feedbacks or even expert opinions, would enable them to be put into an order of priority depending on their plausibility. Thirdly, the computer tool developed is not restricted to natural hazards. Whenever an FMEA is sufficiently complete and of adequate quality, the tool can automate searches for domino-effect failure scenarios. This last point is a very interesting inasmuch as it gives us a glimpse of the tool's capabilities for characterizing multi-hazard vulnerability (earthquakes, high winds, etc.). Fourthly, it would also appear to be of interest to reuse the computer tool with components that have been protected. This would enable evolutions in domino-effect failures to be determined, when compared with the same configuration of installation where components are not protected. Fifthly, on operational levels, the tool would enable us to assess the interest for the system in possessing more resilient designs for certain components. Actually in this context, the four components of the resilience identified by (Cimellaro et al., 2009) could be used for elaborating and implementing resilience strategies. Hence, a given resilience strategy must improve the robustness, the resourcefulness, the redundancy and/or the rapidity capacity of the system. The following proposals provide examples of existing or potential resilience strategies and the associated capacities improved:

- the protection of components that initiate domino-effect failures in order to "break" the propagation within the system increases the robustness capacity of the system;

- temporary measures like the dismantlement of sensitive components before the occurrence of the natural hazard increase the resourcefulness and rapidity capacity of the system;

- measures post-hazard in order to accelerate the recovery such as the quick availability of components to be replaced and trained staff increase the resourcefulness and rapidity capacity of the system.

This study also gives other research perspectives at the urban scale. Firstly, the identified and produced scenarios of disruptions relating to a guided transport system can be expressed through the impacts on population, economic activities, government or other critical infrastructures. It could give an assessment of the consequences of the effects of 
guided transport systems disruptions as a mirror image of the disruptions between critical infrastructures usually expressed through these dimensions.

Acknowledgements This work has been partially supported by the French national project "Ville 10DVille d'idées" ("10D City—City of Ideas": Different Dimensions for Sustainable and Desirable Urban Development Declined in a "Top-Down” Dynamic).

\section{References}

Amblard J, Pams Capoccioni C, Nivon D, Mellal L, De Cesare G, Ghilardi T, Jafarnejad M, Battisacco E (2015) Analysis of ballast transport in the event of overflowing of the drainage system on high speed lines. Int J Railw Technol 4(2):19-43

Bach C, Bouchon S, Fekete A, Birkmann J, Serre D (2013) Adding value to critical infrastructure research and disaster risk management: the resilience concept. SAPI EN S, 6 (2014)

Barroca B, Serre D (2013) Behind the barriers: a resilience conceptual model. SAPI ENS 6:11

Birkmann J, Cardona OD, Carreño ML, Barbat AH, Pelling M, Schneiderbauer S, Welle T (2013) Framing vulnerability, risk and societal responses: the MOVE framework. Nat Hazards 67(2):193-211. doi:10. 1007/s11069-013-0558-5

Bouchon S (2006) The vulnerability of interdependent critical infrastructures systems: epistemological and conceptual state-of-the-art. European Commission - Joint Research Centre”. 103p. Ispra - Italie

Bruneau M, Chang SE, Eguchi RT, Lee GC, O'Rourke TD, Reinhorn AM, Von Winterfeldt D (2003) A framework to quantitatively assess and enhance the seismic resilience of communities. Earthq Spectra 19(4):733-752. doi:10.1193/1.1623497

Buldyrev SV, Parshani R, Paul G, Stanley HE, Havlin S (2010) Catastrophic cascade of failures in interdependent networks. Nature 464(7291):1025-1028

CEU (2008) On the identification and designation of European critical infrastructures and the assessment of the need to improve their protection. Official Journal of the European Communities. Brussels (Belgium), Directive 114

Chamra S (2006) Flooding of the Prague metro during the August 2002 floods. Geol Soc Lond (393)

Cimellaro GP, Arcidiacono V (2013) Resilience-based design for urban cities. In: Serre D, Barroca B, Laganier R (eds) How the concept of resillience is able to improve urban risk management? A temporal and a spatial analysis. CRC Press, Paris, pp 127-141

Cimellaro GP, Reinhorn AM (2010) Multidimensional performance limit state for hazard fragility functions. ASCE J Eng Mech 137(1):47-60

Cimellaro GP, Fumo C, Reinhorn AM, Bruneau M (2009) Quantification of seismic resilience of health care facilities. In: MCEER technical report-MCEER-09-0009. Multidisciplinary Center for Earthquake Engineering Research, Buffalo

Cimellaro GP, Reinhorn AM, Bruneau M (2010) Framework for analytical quantification of disaster resilience. Eng Struct 32(11):3639-3649

Cimellaro GP, Solari D, Bruneau M (2014) Physical infrastructure interdependency and regional resilience index after the 2011 Tohoku earthquake in Japan. Earthq Eng Struct Dynam 43(12):1763-1784

Cochran I (2009) Infrastructures de transport en France: Vulnérabilité au changement climatique et possibilités d'adaptation. Étude Climat $\mathrm{n}^{\circ} 18$, Caisse des Dépôts

Comesb T, Van de Walle B (2014) Measuring disaster resilience: the impact of hurricane sandy on critical infrastructure systems. In: Hiltz SR, Pfaff MS, Plotnick L, Shih PC (eds) Proceedings of the 11th international ISCRAM conference. University Park, Pennsylvania, pp 195-204

Compton K, Ermolieva T, Linnerooth-Bayer J (2002) Integrated flood risk management for urban infrastructure: managing the flood risk to Vienna's Heavy Rail Mass Rapid Transit System. In: Proceedings of second annual IIASA-DPRI meeting "Integrated Disaster Risk Management: Megacity Vulnerability and Resilience". Laxenburg, Austria, pp 1-20

DHS (U.S. Department of Homeland Security) (2006) National Infrastructure Protection Plan. $122 \mathrm{p}$

Duinmeijer AGP, Bouwknegt R (2004) Betrouwbaarheid Railinfrastructuur 2003 (Reliability Rail Infrastructure 2003). Prorail, Eads, Utrecht

ERRAC and UITP (2012) Metro, light rail and tram systems in Europe. Published by ERRAC Roadmaps, The FP7 project of ERRAC - The European Rail Research Advisory Council. $44 \mathrm{p}$

Francis R, Bekera B (2014) A metric and frameworks for resilience analysis of engineered and infrastructure systems. Reliab Eng Syst Saf 121:90-103 
Gallopín GC (2006) Linkages between vulnerability, resilience, and adaptive capacity. Glob Environ Change 16(3):293-303

Gonzva M, Gautier P-E (2014) Résilience des systèmes de transport guidé: du risque de vents traversiers vers le risque hydrologique? In: 2nd international symposium railway geotechnical engineering GEORAIL 2014. Marne-la-Vallée, France: IFSTTAR, pp 407-416

Gonzva M, Diab Y, Barroca B, Gautier P-E (2014) Résilience des systèmes de transport guidé face aux risques naturels. In: Proceedings of Congrès Lambda-Mu 19 de Maîtrise des Risques et Sûreté de Fonctionnement. Dijon, France

Gonzva M, Barroca B, Gautier P-E, Diab Y (2015) A modelling of disruptions cascade effect within a rail transport system facing a flood hazard. In: The 48th ESReDA seminar on critical infrastructures preparedness: status of data for resilience modelling, simulation and analysis. Wroclaw, Poland

Kröger W (2008) Critical infrastructures at risk: a need for a new conceptual approach and extended analytical tools. Reliab Eng Syst Saf 93(12):1781-1787. doi:10.1016/j.ress.2008.03.005

La Porte TM (2006) Organizational strategies for complex system resilience, reliability and adaptation. In: Auerswald PE, Branscomb LM, La Porte TM, Michel-Kerjan EO (eds) Seeds of disaster roots of response, how private action can reduce public vulnerability. Cambridge University Press, Cambridge, pp 135-153

Le Moigne JL (1999) La modélisation des systèmes complexes. Dunod, Paris

Lhomme S (2012) Les réseaux techniques comme vecteur de propagation des risques en milieu urbain-Une contribution théorique et pratique à l'analyse de la résilience urbaine. Ph.D. thesis, Paris-Diderot University

Lhomme S, Serre D, Diab Y, Laganier R (2010) Les réseaux techniques face aux inondations ou comment définir des indicateurs de performance de ces réseaux pour évaluer la résilience urbaine. Bulletin de l'association des géographes français, pp 487-502

Lhomme S, Serre D, Diab Y, Laganier R (2011) A methodology to produce interdependent networks disturbance scenarios. In: Proceedings of international conference on vulnerability and risk analysis and management, 11-13 avril 2011, ASCE, University of Maryland, Hyattsville, USA, pp 724-731

New York State Energy Research and Development Authority (NYSERDA) (2011) Responding to climate change in New York State: the climAID integrated assessment for effective climate change adaptation in New York State: final report, November. Albany, NY

O'Rourke TD (2007) Critical infrastructure, interdependencies, and resilience. Bridge-Washington-National Academy of Engineering 37(1):22-29

Oslakovic IS, terMaat H, Hartmann A, Dewulf G (2013) Risk assessment of climate change impacts on railway infrastructure. In: Carrillo $\mathrm{P}$, Chinowsky $\mathrm{P}$ (eds) Proceedings of engineering project organization conference. Devil's Thumb Ranch, Colorado

PCCIP (2001) President's commission on critical infrastructure protection, Report on the Federal Agenda in Critical Infrastructure Protection Research and Development

Public Safety Canada (PSC) (2009) National strategy for critical infrastructure. ISBN: 978-1-100-11248-0

Renschler CS, Frazier AE, Arendt LA, Cimellaro GP, Reinhorn AM, Bruneau M (2010) Developing the "PEOPLES" resilience framework for defining and measuring disaster resilience at the community scale. In: Proceedings of the 9th U.S. National and 10th Canadian conference on earthquake engineering. Toronto, Ontario, Canada

Rinaldi SM, Peerenboom JP, Kelly TK (2001) Identifying, understanding, and analyzing critical infrastructure interdependencies. IEEE Control Syst Mag 21(6):11-25

Robert B, Morabito L (2011) Reducing the vulnerability of critical infrastructures: methodological manual. Presse International Polytechnique, Montréal

Serre D (2005) Évaluation de la performance des digues de protection contre les inondations - Modélisation de critères de décision dans un Système d'Information Géographique. Ph.D. thesis, Marne-la-Vallée University

Serre D, Peyras L, Curt C, Boissier D, Diab Y (2007) Assessment of civil engineering hydraulic infrastructures. Can Geotech J 44:1298-1313

Suarez P, Anderson W, Mahal V, Lakshmanan TR (2005) Impacts of flooding and climate change on urban transportation: a systemwide performance assessment of the Boston Metro Area. Transp Res Part D Transp Environ 10(3):231-244

UN-Habitat (2012) State of the world's cities 2012/2013: prosperity of Cities. UN-HABITAT, Geneve

Ventura CE, Juarez Garcia H, Marti JM (2010) Understanding Interdependencies among Critical Infrastructures. In: Proceedings of the 9th U.S. National and 10th Canadian conference on earthquake engineering. Toronto, Ontario, Canada

Vuillet M (2012) Élaboration d'un modèle d'aide à la décision basé sur une approche probabiliste pour l'évaluation de la performance des digues fluviales. Ph.D. thesis, Paris-Est Marne-la-Vallée University 
Weather Extremes: Impacts on Transport Systems and Hazards for European Regions (2012) Research project WEATHER, funded under the 7th framework program of the European Commission. Project co-ordinator: Fraunhofer-ISI. Karlsruhe

Zimmerman R, Restrepo CE (2006) The next step: quantifying infrastructure interdependencies to improve security. Int J Crit Infrastruct 2:215

Zwingelstein G (1996) La maintenance basée sur la fiabilité. Guide pratique d'application de la RCM. Hermès Editions, Paris 